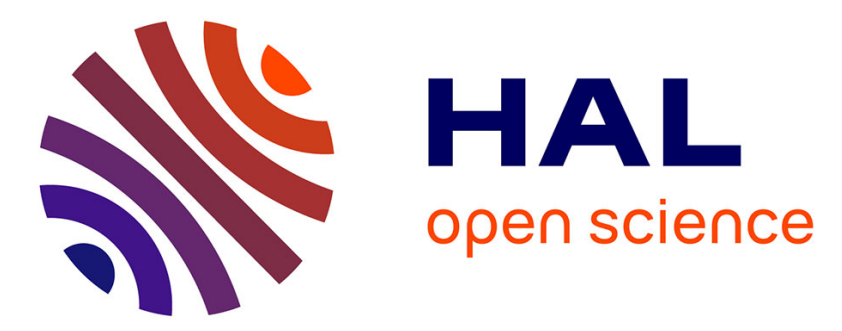

\title{
Fertility preservation after fertility-sparing surgery in women with borderline ovarian tumours
}

\author{
S. Khiat, M. Provansal, P. Bottin, J. Saias-Magnan, Catherine \\ Metzler-Guillemain, Blandine Courbiere
}

\section{- To cite this version:}

S. Khiat, M. Provansal, P. Bottin, J. Saias-Magnan, Catherine Metzler-Guillemain, et al.. Fertility preservation after fertility-sparing surgery in women with borderline ovarian tumours. European Journal of Obstetrics \& Gynecology and Reproductive Biology, 2020, 253, pp.65-70. 10.1016/j.ejogrb.2020.07.053 . hal-02926007

\section{HAL Id: hal-02926007 https://hal.science/hal-02926007}

Submitted on 31 Aug 2020

HAL is a multi-disciplinary open access archive for the deposit and dissemination of scientific research documents, whether they are published or not. The documents may come from teaching and research institutions in France or abroad, or from public or private research centers.
L'archive ouverte pluridisciplinaire HAL, est destinée au dépôt et à la diffusion de documents scientifiques de niveau recherche, publiés ou non, émanant des établissements d'enseignement et de recherche français ou étrangers, des laboratoires publics ou privés. 


\title{
Fertility preservation after fertility-sparing surgery in women with borderline ovarian tumours
}

\author{
S. Khiat ${ }^{\mathrm{a}}$, M. Provansal ${ }^{\mathrm{b}}$, P. Bottin ${ }^{\mathrm{a}}$, J. Saias-Magnan ${ }^{\mathrm{a}}$, C. Metzler-Guillemain ${ }^{\mathrm{a}, \mathrm{c}}$, \\ B. Courbiere ${ }^{\mathrm{a}, \mathrm{d}, *}$

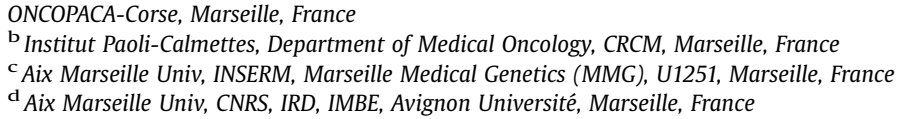

Keywords:

Borderline ovarian tumour

Fertility preservation

Oocyte cryopreservation

Pregnancy

\begin{abstract}
A B S T R A C T
Objective: To present a case series of women with borderline ovarian tumours (BOTs) who underwent oocyte vitrification in addition to fertility-sparing surgery.

Study design: Observational study of all women referred to a French fertility preservation unit between 2015 and 2019 for counselling regarding a fertility preservation (FP) strategy after BOT fertility-sparing surgery. All eligible women underwent one or more cycles of controlled ovarian stimulation (COS) using an antagonist protocol, followed by oocyte retrieval. Metaphase II (MII) oocytes were vitrified. Results: Twenty-five women with BOTs were referred during the study period. Among them, 11 women underwent at least one cycle of COS. One hundred and seven MII oocytes were vitrified. The mean number of vitrified MII oocytes per woman was 9.7 (standard deviation 5.2). Five live births were reported during follow-up of four women with vitrified oocytes: three spontaneous pregnancies, one invitro fertilization cycle with fresh embryo transfer, and one live birth after return of vitrified oocytes. Conclusion: Conservative surgery for BOTs offers a high spontaneous pregnancy rate but has a higher risk of relapse than radical treatment. Furthermore, women who undergo conservative BOT surgery have a higher risk of surgery-induced premature ovarian failure. Oocyte cryopreservation after COS appears to be an effective technique after the conservative management of BOTs in women of reproductive age. Although the available short-term data are reassuring, further long-term studies evaluating the safety and cost-effectiveness of this systematic FP strategy after BOT fertility-sparing surgery are required.
\end{abstract}

\section{Introduction}

Borderline ovarian tumours (BOTs) are a rare group of ovarian tumours that differ from carcinoma in the absence of stromal invasion [1,2]. BOTs have a good prognosis, and 10-year overall survival is $>90 \%$ [3]. The average age of onset is 45 years, which is 20 years younger than the average age of onset of invasive epithelial ovarian cancer; one-third of patients with BOTs are of childbearing age [4]. Standard treatment involves bilateral salpingo-oophorectomy with or without hysterectomy, and leads to permanent suppression of endocrine and exocrine ovarian

\footnotetext{
* Corresponding author at: Pôle Femmes-Parents-Enfants, Centre ClinicoBiologique d'AMP-CECOS, Plateforme Cancer et Fertilité ONCOPACA-Corse, APHM, La Conception, 147 bd Baille, 13005 Marseille, France.

E-mail address: blandine.courbiere@univ-amu.fr (B. Courbiere).
}

function. Considering the good prognosis of BOT and the global trend to postpone motherhood, fertility preservation (FP) remains a major concern for these women. Fertility-sparing surgery was proposed in 1988 by Lim-Tan et al., who first described cystectomy or unilateral salpingo-oophorectomy with the aim of reducing an impairment in the ovarian reserve and enabling spontaneous pregnancy [5]. The oncologic safety of conservative management of BOTs has been well documented, and despite a higher risk of recurrence compared with radical treatment, no differences have been observed in 10-year overall survival rates [6]. However, these recurrences lead to additional surgeries at high risk of decreasing the ovarian reserve, and conservative treatment does not appear to fully preserve fertility. Several FP techniques, such as controlled ovarian stimulation (COS) for oocyte vitrification, have been proposed in women with BOTs, but limited data are available on the feasibility, safety and effectiveness of this technique [7-9]. This article presents the first case series of women with BOTs who 
underwent FP through COS for oocyte vitrification after fertilitysparing surgery. Specific FP strategies of potential use after conservative surgery in this population are discussed.

\section{Materials and methods}

A retrospective observational study collected medical data from women with BOTs who were referred to a French fertility preservation unit from 2015 to 2019, regardless of the histological type of the BOT. All women had undergone at least one ovarian surgery for BOT before counselling. COS was offered to women who had complete surgery without stromal microinvasion at anatomopathology. The aim of counselling was to inform women of the rate of spontaneous pregnancy without FP, and about the benefits, limits and risks of oocyte vitrification. Moreover, information was given about the chance of a live birth using vitrified-thawed oocytes, taking account of the woman's age and the number of vitrified oocytes. Cobo et al. reported an ongoing pregnancy rate of $35.7 \%$ and a livebirth rate of $41.1 \%$ in women aged $\leq 35$ years who cryopreserved for oncological indications. Before 35 years of age, the cumulative probability of live birth in oncological indications is 9.1\% for five cryopreserved oocytes, $35.8 \%$ for eight cryopreserved oocytes, $42.9 \%$ for 10 cryopreserved oocytes and $61.9 \%$ for 12 cryopreserved oocytes [10].

After a personalized counselling session, and in agreement with the oncologic team and the patient, COS was initiated on Day 2 of the woman's cycle using daily subcutaneous injections of recombinant follicle-stimulating hormone ( $\mathrm{rFSH})$. A gonadotropin-releasing hormone antagonist was co-administered daily, beginning on Day 5, to prevent the surge of luteinizing hormone. Oocyte maturation was triggered with $0.3 \mathrm{mg}$ triptoreline $36 \mathrm{~h}$ prior to transvaginal oocyte retrieval under local or general anaesthesia. Metaphase II (MII) oocytes were vitrified using a closed system (Vit Kit Freeze, Irvine Scientific, Santa Ana, CA, USA). According to the number of MII oocytes cryopreserved, one or more cycles of COS were proposed to accumulate more than 10 mature oocytes. This study was approved by the Ethics Committee at Aix Marseille University ( $\mathrm{N}^{\circ}$ 2019-17-10-003).

\section{Results}

In total, 25 women with BOTs were referred to our centre for FP counselling after undergoing their first fertility-sparing surgery. Their median age was $27.5 \pm 5.6$ years. Most women had an International Federation of Gynaecology and Obstetrics (FIGO) stage I tumour $(80 \%, n=20)$. The other five women were treated for FIGO stage III tumours with non-invasive peritoneal implants. Ten women had prior unilateral oophorectomy (40\%); that was associated with contralateral cystectomy for bilateral BOT for two women. Nine women had unilateral cystectomy (36\%) and seven women had bilateral cystectomy (28\%). The serum level of anti-Müllerian hormone (AMH) after conservative surgery was available for 15 women \{mean 7.8 [standard deviation (SD) 8.6 $\mathrm{pmol} / \mathrm{l}]\}$.

The characteristics of the 11 women who chose to cryopreserve their oocytes are reported in Table 1. In this group, the median age was $26 \pm 5.7$ years. An assessment of ovarian reserve showed a mean serum AMH level of 9.7 (SD 9.8) pmol/l and a mean antral follicle count of 5.3 (SD 2.8). Among these 11 women, eight only had one ovary remaining after surgery.

Among the 14 women who did not choose to cryopreserve their oocytes, eight declined FP after a personalized counselling session. Given the lack of data regarding the long-term risk of COS, fear of increasing the risk of relapse was the main reason why patients declined the offer of FP. Two women were contra-indicated for COS: one because of a concurrent lupus flare-up, and the other for suspicion of associated ovarian microinvasion. Two women wished to postpone the COS cycle, and two patients did not start COS as scheduled for personal reasons.

\section{Outcome of oocyte cryopreservation}

The results of COS cycles are presented in Table 2. The mean duration of COS cycles was 10.8 (SD 2) days, and the mean total dose of gonadotropin required was 3680 (SD 1120) IU. One hundred and fifty-six oocytes were harvested, and 107 MII oocytes were vitrified. The mean numbers of retrieved oocytes and MII vitrified oocytes per woman were 14.1 (SD 6.7) and 9.7 (SD 5.2), respectively. Fifty-four percent of women $(n=6 / 11)$ cryopreserved $\geq 10$ oocytes. One woman underwent five COS cycles, three patients underwent three or two cycles, and four women only underwent one cycle. A single COS cycle was sufficient for two women (Patients 8 and 10), and more than 10 oocytes were retrieved. The median duration of follow-up after COS was $16 \pm 15$ months (7-48).

\section{Fertility outcome}

Fertility outcome is summarized in Table 3. During follow-up, four women achieved a live birth and one woman had two babies.

One woman (Patient 1) wanted to use her cryopreserved oocytes. In May 2015, this 29-year-old patient was initially diagnosed with serous bilateral BOT with peritoneal spread. A right salpingo-oophorectomy, omentectomy and left cystectomy were performed before FP. A blood test of hormone levels before COS showed a diminished ovarian reserve on Day 3 of her cycle, FSH of $9 \mathrm{UI} / \mathrm{l}$, estradiol (E2) of $92 \mathrm{pmol} / \mathrm{L}$ and AMH of $5.3 \mathrm{pmol} / \mathrm{L}$. Between September 2015 and January 2016, three cycles of COS led to vitrification of 12 MII oocytes from the residual left ovary. In March 2016, after oncological counselling, surgical radical treatment was completed with left salpingo-oophorectomy. Approximately 2 months later, hormone replacement therapy was prescribed for embryo transfer (ET): $4 \mathrm{mg}$ of oral E2 per day for 13 days until endometrial thickness $>8 \mathrm{~mm}$. Next, $600 \mathrm{mg}$ of vaginal progesterone was administered daily 3 days before Day 3 ET. In May 2016, four oocytes were warmed and four diploid embryos were obtained after intracytoplasmic sperm injection (ICSI). Due to a history of two caesarean sections, a single ET was performed and two additional embryos were frozen. No pregnancy was obtained. In August 2016, a second ET of a single frozenthawed embryo led to a singleton pregnancy. A 3760-g healthy girl was born by caesarean section at 38 weeks of pregnancy. In June 2020 , this patient had not experienced any recurrence, and underwent sonographic follow-up every 6 months.

Patient 5 was a 27-year-old woman who was referred after her first surgery of bilateral serous BOT, treated with left oophorectomy and right cystectomy. Blood tests of ovarian reserve on Day 2 of her cycle showed FSH of $8.6 \mathrm{UI} / \mathrm{l}, \mathrm{E} 2$ of $28 \mathrm{pmol} / \mathrm{l}$ and AMH of 12.5 $\mathrm{pmol} / \mathrm{l}$. The total antral follicle count was 6 . After three cycles of COS between 2015 and 2017, only five MII oocytes were cryopreserved. Two years later, she desired a pregnancy. Spontaneous pregnancy was not possible due to a right hydrosalpinx. Due to the low number of cryopreserved oocytes and a sufficient ovarian reserve (AMH $9.3 \mathrm{pmol} / \mathrm{l}$ ), a new COS cycle was performed for ICSI-in-vitro fertilization (IVF). Two mature oocytes were retrieved and fertilized, and led to the transfer of two fresh diploid Day 3 embryos. The patient achieved a singleton pregnancy with a 3360-g healthy newborn.

Two women reported spontaneous pregnancies after oocyte cryopreservation. One woman (Patient 10) achieved two spontaneous pregnancies with two term deliveries 1 and 3 years after conservative BOT management. The second woman (Patient 6) 
Table 1

Characteristics of women who cryopreserved oocytes after conservative surgery for borderline ovarian tumour (BOT).

\begin{tabular}{|c|c|c|c|c|c|c|c|}
\hline $\begin{array}{l}\text { Patient } \\
\text { no. }\end{array}$ & $\begin{array}{l}\text { Age } \\
\text { (years) }\end{array}$ & Localization & $\begin{array}{l}\text { FIGO } \\
\text { stage }\end{array}$ & $\begin{array}{l}\text { Histological } \\
\text { type }\end{array}$ & $\begin{array}{l}\text { Ovarian surgery prior to oocyte } \\
\text { cryopreservation }\end{array}$ & $\begin{array}{l}\text { Follow-up after oocyte } \\
\text { cryopreservation }\end{array}$ & $\begin{array}{l}\text { Duration of } \\
\text { follow-up } \\
\text { (months) }\end{array}$ \\
\hline 1 & 29 & $\begin{array}{l}\text { Bilateral BOTs }+ \\
\text { non-invasive implants } \\
\text { in the omentum }\end{array}$ & IIIA & Serous & $\begin{array}{l}\text { Unilateral right oophorectomy, } \\
\text { omentectomy, left cystectomy }\end{array}$ & $\begin{array}{l}\text { Radical surgery with left oophorectomy } \\
\text { after COS (three cycles) and oocyte } \\
\text { vitrification. Return of vitrified oocytes. } \\
\text { Live birth (girl, } 3760 \mathrm{~g}, 38 \mathrm{GW} \text { ) after } \\
\text { ICSI-IVF on frozen-thawed oocytes }\end{array}$ & 48 \\
\hline 2 & 18 & $\begin{array}{l}\text { Unilateral BOT + } \\
\text { peritoneal implants }\end{array}$ & IIIA & Serous & $\begin{array}{l}\text { Unilateral left oophorectomy, } \\
\text { omentectomy }\end{array}$ & No recurrence & 24 \\
\hline 3 & 21 & Unilateral BOT & IA & Mucinous & Unilateral right oophorectomy & No recurrence & 7 \\
\hline 4 & 28 & $\begin{array}{l}\text { Unilateral BOT }+ \text { non } \\
\text { invasive peritoneal and } \\
\text { caecal implants }\end{array}$ & IIIA & Serous & $\begin{array}{l}\text { Unilateral left cystectomy, resection of } \\
\text { peritoneal implants }\end{array}$ & $\begin{array}{l}\text { Recurrence at } 9 \text { months: treated by left } \\
\text { oophorectomy. Contralateral } \\
\text { recurrence at } 14 \text { months: radical } \\
\text { treatment by right oophorectomy }\end{array}$ & 12 \\
\hline 5 & 27 & Bilateral BOTs & IB & Serous & $\begin{array}{l}\text { Unilateral right oophorectomy, } \\
\text { contralateral cystectomy }\end{array}$ & $\begin{array}{l}\text { Contralateral recurrence at } 12 \text { months: } \\
\text { conservative treatment with recurrent } \\
\text { cystectomy on left ovary. Live birth (girl, } \\
3360 \mathrm{~g}, 39 \mathrm{GW} \text { ) after COS, oocyte pick- } \\
\text { up from the remaining ovary. ICSI-IVF } \\
\text { (two MII oocytes) and fresh embryo } \\
\text { transfer }\end{array}$ & 36 \\
\hline 6 & 27 & Unilateral BOT & IA & Serous & Unilateral left oophorectomy & $\begin{array}{l}\text { No recurrence. Spontaneous pregnancy } \\
\text { - live birth } 36 \text { months after surgery }\end{array}$ & 36 \\
\hline 7 & 25 & Unilateral BOT & IA & Serous & Unilateral left cystectomy & No recurrence & 7 \\
\hline 8 & 38 & Unilateral BOT & IA & Endometrioid & Unilateral right cystectomy & No recurrence & 16 \\
\hline 9 & 21 & Bilateral BOTs & IB & Serous & $\begin{array}{l}\text { Unilateral right oophorectomy, } \\
\text { contralateral left cystectomy }\end{array}$ & No recurrence & 24 \\
\hline 10 & 26 & Unilateral BOT & IA & Mucinous & Unilateral right oophorectomy & $\begin{array}{l}\text { No recurrence. Spontaneous pregnancy } \\
\text { - live births } 12 \text { and } 36 \text { months after } \\
\text { surgery }\end{array}$ & 48 \\
\hline 11 & 19 & Unilateral BOT & IA & Mucinous & Unilateral right oophorectomy & No recurrence & 14 \\
\hline
\end{tabular}

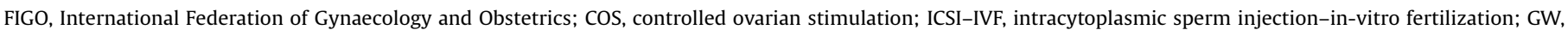
gestational weeks; MII, metaphase II.

achieved a spontaneous pregnancy with a healthy baby born by caesarean section at term. To date, follow-up of these women has not detected recurrence at, respectively, 48 and 12 months since COS. For these two women, their vitrified oocytes (13 and six MII oocytes, respectively) provide an additional chance of pregnancy in the event of a decreased ovarian reserve induced by further surgery or a postponed desire for future parenthood.

One case of BOT recurrence was reported after one cycle of COS in the FP group (Patient 4). This 28-year-old woman with FIGO stage IIIA unilateral serous BOT received unilateral cystectomy by laparoscopy with excision of caecal and peritoneal non-invasive implants and omentectomy. One cycle of COS enabled cryopreservation of four MII oocytes. Nine months after COS, she presented with ipsilateral relapse and underwent oophorectomy. She did not wish to perform a supplementary COS cycle. Five months later, she presented with contralateral relapse that was treated with contralateral oophorectomy. After 36 months of follow-up, this patient has not experienced recurrence, continues to be monitored, and does not currently wish to use her cryopreserved oocytes.

\section{Discussion}

BOTs occur in young women who have not always completed their families, and the preservation of their long-term fertility is a paramount challenge. Oocyte cryopreservation appears to be a feasible and efficient FP technique in women of reproductive age after conservative surgery for BOT. To the authors'knowledge, this is the first reported case series of women with BOTs who have benefited from this FP strategy. The first live birth was reported by Porcu et al. in 2008, and the authors believe that the present study reports the second live birth after returning cryopreserved oocytes to a woman following BOT surgery [8].
Fertility-sparing surgery effectively preserves fertility and allows spontaneous pregnancies. The cumulative spontaneous pregnancy rate is $50-60 \%$ after conservative surgery [6,11]. Nevertheless, the recurrence rate is higher after this conservative strategy, and is evaluated at 20-30\% [12,13]. Despite the higher risk of recurrence, no difference in survival rate has been observed, which remains at $>90 \%$, and the risk of progression to invasive carcinoma appears to be low, estimated at 2-3\% [1]. In women with bilateral BOTs, which account for $40 \%$ of serous BOTs, a randomized controlled trial compared bilateral cystectomy with oophorectomy plus contralateral cystectomy. At 11-year follow-up, women who underwent bilateral cystectomy had a significantly shorter time to first live birth and a higher relative rate (RR) of live birth [RR $=8.05$ (95\% confidence interval 1.20-9.66; $p<0.01$ )]. The RR of recurrence did not differ significantly between the two groups, but the time to first recurrence was significantly shorter for the bilateral cystectomy group (16.2 months vs 48 months; $p<0.01$ ) [14,15]. Recent French guidelines also recommend bilateral cystectomy in women with bilateral BOTs who wish to preserve their fertility [16]. Despite the efficiency of fertility-sparing surgery, the increased rate of relapse carries a higher risk of additional surgery than radical treatment. Every ovarian surgical procedure risks reducing the ovarian reserve and inducing premature ovarian insufficiency [17]. In a cohort study by Chevrot et al. with 52 women of childbearing age, the pregnancy rate after conservative BOT treatment was $63 \%$, but $26 \%$ of women required postoperative assisted reproductive medicine to conceive [18]. In a retrospective cohort study of 535 women who underwent conservative surgery, Delle Marchette et al. showed that each ovarian surgery reduced the probability of achieving a spontaneous pregnancy by $40 \%$ [11].

Considering the global trend to postpone motherhood in developed countries and the high survival rate of women with early-stage BOTs, additional FP techniques should be offered to 
Table 2

Results of controlled ovarian stimulation (COS) cycles for oocyte cryopreservation in women who underwent conservative surgery for borderline ovarian tumours.

\begin{tabular}{|c|c|c|c|c|c|c|c|}
\hline Patient no. & $\begin{array}{l}\text { Baseline AMH } \\
\text { level, }(\mathrm{pmol} / \mathrm{l})\end{array}$ & $\begin{array}{l}\text { Antral follicle } \\
\text { count }\end{array}$ & $\begin{array}{l}\text { Stimulation } \\
\text { cycles }\end{array}$ & $\begin{array}{l}\text { Total dose of gonadotropins } \\
\text { required for stimulation (IU) }\end{array}$ & $\begin{array}{l}\text { Peak E2 level } \\
(\mathrm{pmol} / \mathrm{l})\end{array}$ & $\begin{array}{l}\text { Oocytes } \\
\text { retrieved }(n)\end{array}$ & $\begin{array}{l}\text { Cryopreserved } \\
\text { MII oocytes }(n)\end{array}$ \\
\hline \multirow[t]{4}{*}{1} & 10 & 7 & Cycle 1 & 4125 & 1575 & 6 & 5 \\
\hline & & & Cycle 2 & 3750 & 1000 & 5 & 4 \\
\hline & & & Cycle 3 & 3375 & 468 & 3 & 3 \\
\hline & & & & & & 14 & 12 \\
\hline \multirow[t]{4}{*}{2} & NA & 9 & Cycle 1 & 2700 & 488 & 7 & 4 \\
\hline & & & Cycle 2 & 2700 & 488 & 10 & 7 \\
\hline & & & Cycle 3 & 2100 & 554 & 8 & 7 \\
\hline & & & & & & 25 & 18 \\
\hline 3 & 1.3 & 3 & & 3600 & 485 & 1 & 1 \\
\hline 4 & 3.9 & 5 & & 2400 & 1400 & 9 & 4 \\
\hline \multirow[t]{4}{*}{5} & 12.5 & 8 & Cycle 1 & 3000 & 3966 & 3 & 2 \\
\hline & & & Cycle 2 & 2400 & 537 & 3 & 2 \\
\hline & & & Cycle 3 & 2400 & 1345 & 2 & 1 \\
\hline & & & & & & 8 & 5 \\
\hline \multirow[t]{3}{*}{6} & 2.9 & NA & Cycle 1 & 4500 & 300 & 8 & 3 \\
\hline & & & Cycle 2 & 4800 & 201 & 6 & 3 \\
\hline & & & & & & 14 & 6 \\
\hline \multirow[t]{3}{*}{7} & 13.5 & 8 & Cycle 1 & 4200 & 586 & 8 & 5 \\
\hline & & & Cycle 2 & 3900 & 265 & 10 & 7 \\
\hline & & & & & & 18 & 12 \\
\hline 8 & 7.8 & 8 & & 4050 & 2596 & 16 & 15 \\
\hline \multirow[t]{6}{*}{9} & 0.4 & NA & Cycle 1 & 6300 & 841 & 0 & 0 \\
\hline & & & Cycle 2 & 4950 & 1395 & 3 & 0 \\
\hline & & & Cycle 3 & 4950 & 1563 & 3 & 3 \\
\hline & & & Cycle 4 & 4950 & 699 & 8 & 4 \\
\hline & & & Cycle 5 & 4950 & 924 & 9 & 6 \\
\hline & & & & & & 23 & 13 \\
\hline \multirow[t]{3}{*}{10} & NA & 10 & Cycle 1 & 3000 & 1588 & 9 & 7 \\
\hline & & & Cycle 2 & 3300 & 926 & 7 & 6 \\
\hline & & & & & & 16 & 13 \\
\hline 11 & 35.7 & NA & & 2000 & 3000 & 12 & 8 \\
\hline
\end{tabular}

AMH, anti-Müllerian hormone; E2, estradiol; MII, metaphase II; NA, not available.

Table 3

Fertility outcome of women who cryopreserved oocytes after conservative surgery for borderline ovarian tumours (BOTs).

\begin{tabular}{|c|c|c|}
\hline Patient no. & Characteristics & Fertility outcomes \\
\hline 1 & $\begin{array}{l}\text { 29-year-old women with bilateral serous FIGO stage IIIA } \\
\text { tumour with non-invasive implants in the omentum treated by } \\
\text { right oophorectomy, left cystectomy and omentectomy. FP } \\
\text { strategy was discussed with oncologists: several COS cycles for } \\
\text { banking oocytes on the remaining left ovary, immediately } \\
\text { followed by left oophorectomy }\end{array}$ & $\begin{array}{l}\text { Three cycles of COS - } 12 \text { MII cryopreserved oocytes. Return of } \\
\text { cryopreserved oocytes } 2 \text { months after left oophorectomy. One live birth } \\
\text { after ICSI-IVF on frozen-thawed oocytes and embryo transfer after } \\
\text { endometrial preparation with hormone replacement therapy (3760-g } \\
\text { healthy girl, } 38 \mathrm{GW} \text { ) }\end{array}$ \\
\hline 5 & $\begin{array}{l}\text { 27-year-old women with bilateral serous FIGO stage IB tumour } \\
\text { treated by left oophorectomy and right cystectomy }\end{array}$ & $\begin{array}{l}\text { Three cycles of COS after first BOT surgery - five MII cryopreserved } \\
\text { oocytes. No recurrence after COS. Thirty-four months after BOT surgery, } \\
\text { desire for pregnancy: IVF because of bilateral hydrosalpinx and despite } \\
\text { a low residual ovarian reserve (AMH } 9.3 \text { pmol/l). One COS cycle was } \\
\text { performed for ICSI-IVF, pick-up of two mature oocytes and transfer of } \\
\text { two fresh embryos. Live birth of a } 3360 \text {-g healthy boy at } 39 \mathrm{GW}\end{array}$ \\
\hline 6 & $\begin{array}{l}\text { 27-year-old women with unilateral left serous FIGO stage IA } \\
\text { tumour treated by unilateral oophorectomy }\end{array}$ & $\begin{array}{l}\text { Two cycles of COS - six MII cryopreserved oocytes. No recurrence after } \\
\text { COS. One spontaneous pregnancy and one live birth } 36 \text { months after } \\
\text { BOT surgery. No oocyte return }\end{array}$ \\
\hline 10 & $\begin{array}{l}\text { 26-year-old women with unilateral mucinous FIGO stage IA } \\
\text { tumour treated by unilateral right oophorectomy }\end{array}$ & $\begin{array}{l}\text { Two cycles of COS - } 13 \text { MII cryopreserved oocytes. Two spontaneous } \\
\text { pregnancies and two live births ( } 1 \text { and } 3 \text { years after BOT surgery). No } \\
\text { oocyte return. No recurrence after COS }\end{array}$ \\
\hline
\end{tabular}

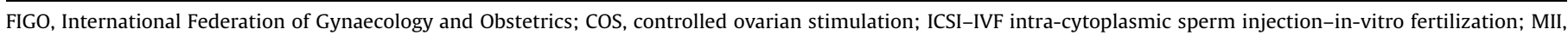
metaphase II; GW, gestational weeks; FP, fertility preservation; AMH, anti-Müllerian hormone.

women who benefited from conservative management and who wish to postpone maternity [19]. To date, only a few case reports have been published that report additional FP strategies for women with BOTs. Gallot et al. reported 'emergency' IVF for a woman with in-situ FIGO stage III BOT who achieved a live birth after radical surgical treatment and a frozen-thawed embryo transfer (ET) [20]. Oocyte retrieval was performed 2 days before bilateral oophorectomy. Sixteen MII oocytes were harvested and fertilized, and 10 embryos were cryopreserved. Three other case reports have described BOT FP using in-vitro maturation of immature oocytes $[7,21,22]$. In two cases, in a context of radical surgery for BOT recurrence, oocytes were harvested ex vivo in a laboratory from the excised ovarian tissue and were fertilized after in-vitro maturation. Two live births were reported after frozen-thawed ET issued from matured oocytes [21,22].

To the authors' knowledge, only a few case reports of oocyte cryopreservation after conservative BOT surgery and COS have been published $[8,23]$. The first live birth was described by Porcu et al., who reported a 26 -year-old woman with a FIGO stage IA serous BOT treated with salpingo-oophorectomy [8]. After a disease-free delay of 2 years, COS was performed and seven mature oocytes were cryopreserved. She presented with recurrence 6 
Table 4

Key points for preserving fertility in women of reproductive age treated for borderline ovarian tumours (BOTs)

1. Information should be provided to women about the risk of a decrease in ovarian reserve induced by surgical treatment of BOTs

2. Fertility counselling should be offered systematically to women of reproductive age with BOTs

3. Conservative surgical treatment helps to preserve fertility in women with early-stage BOTs and allows a high rate of spontaneous pregnancies

4. Due to a higher risk of recurrence, conservative surgical treatment may lead to repeated ovarian surgeries that justify offering a complementary FP technique

5. When conservative BOT treatment is indicated, ovarian stimulation should be considered after complete removal of the BOT

6. Performing one or numerous COS cycles to cryopreserve mature oocytes after the first conservative BOT surgery may ensure oocyte preservation in the case of recurrence

BOT, borderline ovarian tumour; FP, fertility preservation; COS, controlled ovarian stimulation.

months later and a contralateral salpingo-oophorectomy was performed. The patient wished to use her oocytes 4 years later, resulting in a twin pregnancy, and two healthy girls were born at 38 weeks of gestation. Other strategies described COS with in-situ BOT, immediately followed on the day of oocyte pick-up by oophorectomy and ex-vivo oocyte retrieval for in-vitro maturation $[9,24]$. No reports of the use of these frozen oocytes have been published to date. This 'one-shot' FP technique does not allow the patient to undergo repeated cycles of COS which might be useful to increase the number of cryopreserved oocytes, particularly for women who have undergone one or more ovarian surgeries. As described by Fillipi et al., COS could also be discussed upon recurrence, before a new conservative surgery. This approach provides the advantages of conservative treatment and allows better targeting of women with a real need for oocyte cryopreservation. Indeed, there are no data to date that have studied the costeffectiveness of COS for oocyte cryopreservation given the high rate of spontaneous pregnancies after conservative BOT surgery [23].

Available evidence suggests that the use of infertility drugs for ovarian stimulation is safe in women with BOTs after surgery. The recurrence rate does not appear to be higher in women who had both conservative surgery and infertility drugs. The meta-analysis of Daraï et al. reported 105 women who were treated with infertility drugs after conservative BOT surgery [6]. The recurrence rate was $27 \%$, similar to women treated with conservative surgery who did not receive infertility drugs. Denschlag et al. reported a recurrence rate of $19 \%$ in a systematic review including 62 women who received ovarian stimulation after conservative BOT treatment [25]. Basille et al. studied the stimulatory effect of FSH or E2 on in-vitro cultured BOT cells [26]. No difference in growth was observed between exposed and control cells, despite the presence of hormonal receptors on BOT cells, suggesting that gonadotropins might be used in women after conservative surgery for BOT. Data are not available on the safety of COS in women with in-situ ovarian tumours.

Key points of the FP strategy in women with BOTs are summarized in Table 4. As histopathological analysis of the ovarian cyst is necessary to eliminate an invasive carcinoma, complete removal of the ovarian tumour should be performed before FP [27]. As recommended by the guidelines of the American Society of Clinical Oncology, physicians caring for women of reproductive age with BOTs should refer their patients to a fertility preservation unit for counselling prior to the first recurrence to assess their ovarian reserve and inform women about the possibilities of FP. All decisions should be discussed in a multidisciplinary meeting $[28,29]$. The authors propose an FP strategy for women with BOTs in which one or more cycles of COS are performed to preserve at least 10-15 oocytes and preserve future fertility after the first conservative surgery. As suggested by Cobo et al., the preservation of 12 vitrified oocytes prior to 35 years of age results in a cumulative livebirth rate of $61.9 \%$ [10]. This strategy should be proposed to women, regardless of whether or not they have a current desire for pregnancy. However, larger cohort studies with a long duration of follow-up are needed to evaluate the costeffectiveness of a systematic FP strategy after the first BOT surgery.

\section{Conclusion}

Although spontaneous fertility is $>50 \%$ after conservative surgery, additional FP approaches are needed due to a risk of recurrence in women who wish to postpone motherhood. This article reports the first case series of women who have preserved their fertility by oocyte cryopreservation following conservative BOT surgery. In the authors' opinion, performing repeated COS cycles for oocyte cryopreservation after the first conservative BOT surgery represents an interesting and safe strategy, allowing oocyte banking and the possibility of radical surgery in the case of recurrence. However, although these short-term data are reassuring, further long-term studies evaluating the safety and costeffectiveness of this systematic FP strategy following BOT fertilitysparing surgery are required.

\section{Funding}

None.

\section{Declaration of Competing Interest}

None declared.

\section{References}

[1] Morice P, Uzan C, Fauvet R, Gouy S, Duvillard P, Darai E. Borderline ovarian tumour: pathological diagnostic dilemma and risk factors for invasive or lethal recurrence. Lancet Oncol 2012;13:e103-115.

[2] Vasconcelos I, Darb-Esfahani S, Sehouli J. Serous and mucinous borderline ovarian tumours: differences in clinical presentation, high-risk histopathological features, and lethal recurrence rates. $\mathrm{Br} \mathrm{J}$ Obstet Gynaecol 2016;123:498-508.

[3] Trimble CL, Kosary C, Trimble EL. Long-term survival and patterns of care in women with ovarian tumors of low malignant potential. Gynecol Oncol 2002;86:34-7.

[4] Skírnisdóttir I, Garmo H, Wilander E, Holmberg L Borderline ovarian tumors in Sweden 1960-2005: trends in incidence and age at diagnosis compared to ovarian cancer. Int J Cancer 2008;123:1897-901.

[5] Lim-Tan SK, Cajigas HE, Scully RE. Ovarian cystectomy for serous borderline tumors: a follow-up study of 35 cases. Obstet Gynecol 1988;72:775-81.

[6] Daraï E, Fauvet R, Uzan C, Gouy S, Duvillard P, Morice P. Fertility and borderline ovarian tumor: a systematic review of conservative management, risk of recurrence and alternative options. Hum Reprod Update 2013;19:151-66.

[7] Huang JYJ, Buckett WM, Gilbert L, Tan SL, Chian R-C. Retrieval of immature oocytes followed by in vitro maturation and vitrification: a case report on a new strategy of fertility preservation in women with borderline ovarian malignancy. Gynecol Oncol 2007:105:542-4.

[8] Porcu E, Venturoli S, Damiano G, et al. Healthy twins delivered after oocyte cryopreservation and bilateral ovariectomy for ovarian cancer. Reprod Biomed Online 2008; 17:265-7.

[9] Fatemi HM, Kyrou D, Al-Azemi M, et al. Ex-vivo oocyte retrieval for fertility preservation. Fertil Steril 2011;95:1787 e15-7.

[10] Cobo A, García-Velasco J, Domingo J, Pellicer A, Remohí J. Elective and oncofertility preservation: factors related to IVF outcomes. Hum Reprod 2018;33:2222-31.

[11] Delle Marchette M, Ceppi L, Andreano A, et al. Oncologic and fertility impact of surgical approach for borderline ovarian tumours treated with fertility sparing surgery. Eur J Cancer 2019;111:61-8.

[12] Tinelli R, Tinelli A, Tinelli FG, Cicinelli E, Malvasi A. Conservative surgery for borderline ovarian tumors: a review. Gynecol Oncol 2006;100:185-91.

[13] Uzan C, Kane A, Rey A, Gouy S, Duvillard P, Morice P. Outcomes after conservative treatment of advanced-stage serous borderline tumors of the ovary. Ann Oncol Off J Eur Soc Med Oncol 2010;21:55-60. 
[14] Palomba S, Zupi E, Russo T, et al. Comparison of two fertility-sparing approaches for bilateral borderline ovarian tumours: a randomized controlled study. Hum Reprod 2007;22:578-85.

[15] Palomba S, Falbo A, Del Negro S, et al. Ultra-conservative fertility-sparing strategy for bilateral borderline ovarian tumours: an 11-year follow-up. Hum Reprod 2010;25:1966-72.

[16] Canlorbe G, Lecointre L, Chauvet P, Azaïs H, Fauvet R, Uzan C. [Borderline ovarian tumours: CNGOF guidelines for clinical practice - therapeutic management of early stages]. Gynecol Obstet Fertil Senol 2020, doi:http:// dx.doi.org/10.1016/j.gofs.2020.01.016.

[17] Pergialiotis V, Prodromidou A, Frountzas M, Bitos K, Perrea D, Doumouchtsis SK. The effect of bipolar electrocoagulation during ovarian cystectomy on ovarian reserve: a systematic review. Am J Obstet Gynecol 2015;213:620-8.

[18] Chevrot A, Pouget N, Bats A-S, et al. Fertility and prognosis of borderline ovarian tumor after conservative management: results of the multicentric OPTIBOT study by the GINECO \& TMRG group. Gynecol Oncol 2020;157:29-35.

[19] Mills M, Rindfuss RR, McDonald P, te Velde E. ESHRE Reproduction and Society Task Force. Why do people postpone parenthood? Reasons and social policy incentives. Hum Reprod Update 2011;17:848-60.

[20] Gallot D, Pouly JL, Janny L, et al. Successful transfer of frozen-thawed embryos obtained immediately before radical surgery for stage IIIa serous borderline ovarian tumour: case report. Hum Reprod 2000;15:2347-50.

[21] Uzelac PS, Delaney AA, Christensen GL, Bohler HCL, Nakajima ST. Live birth following in vitro maturation of oocytes retrieved from extracorporeal ovarian tissue aspiration and embryo cryopreservation for 5 years. Fertil Steril 2015;104:1258-60.
[22] Prasath EB, Chan MLH, Wong WHW, et al. First pregnancy and live birth resulting from cryopreserved embryos obtained from in vitro matured oocytes after oophorectomy in an ovarian cancer patient. Hum Reprod 2014;29:276-8.

[23] Filippi F, Martinelli F, Somigliana E, Franchi D, Raspagliesi F, Chiappa V. Oocyte cryopreservation in two women with borderline ovarian tumor recurrence. J Assist Reprod Genet 2020;37:1213-6.

[24] Bocca S, Dedmond D, Jones E, Stadtmauer L, Oehninger S. Successful extracorporeal mature oocyte harvesting after laparoscopic oophorectomy following controlled ovarian hyperstimulation for the purpose of fertility preservation in a patient with borderline ovarian tumor. J Assist Reprod Genet 2011;28:771-2.

[25] Denschlag D, von Wolff M, Amant F, et al. Clinical recommendation on fertility preservation in borderline ovarian neoplasm: ovarian stimulation and oocyte retrieval after conservative surgery. Gynecol Obstet Invest 2010;70:160-5.

[26] Basille C, Olivennes F, Le Calvez J, et al. Impact of gonadotrophins and steroid hormones on tumour cells derived from borderline ovarian tumours. Hum Reprod 2006;21:3241-5.

[27] Raad J, Rolland L, Grynberg M, Courbiere B, D’argent EM. [Borderline ovarian tumours: CNGOF guidelines for clinical practice - fertility]. Gynecol Obstet Fertil Senol 2020, doi:http://dx.doi.org/10.1016/j.gofs.2020.01.020.

[28] Oktay K, Harvey BE, Partridge AH, et al. Fertility preservation in patients with cancer: ASCO clinical practice guideline update. J Clin Oncol 2018;36:19942001.

[29] Mangili G, Somigliana E, Giorgione V, et al. Fertility preservation in women with borderline ovarian tumours. Cancer Treat Rev 2016;49:13-24. 